\title{
On the properties and composition of the protoxide of gold
}

\section{M.L. Figuier}

To cite this article: M.L. Figuier (1844) On the properties and composition of the protoxide of gold, Philosophical Magazine Series 3, 25:165, 237-239, DOI: 10.1080/14786444408644979

To link to this article: http://dx.doi.org/10.1080/14786444408644979

曲 Published online: 30 Apr 2009.

Submit your article to this journal $\pi$

Џ Article views: 2

Q View related articles ¿ 
This salt is composed of

\begin{tabular}{lr} 
Chloric acid .. & 38.49 \\
Oxide of lead. & 56.92 \\
Water $\ldots .$. & 4.59 \\
\hline & $\frac{100}{}$
\end{tabular}

Chlorate of Silver.--A neutral solution of this salt is obtained by dissolving oxide of silver in chloric acid; this yields by evaporation distinct prismatic crystals; chlorate of silver is anhydrous; it dissolves in about five parts of cold water, and likewise in alcohol without suffering alteration; it fuses at $446^{\circ}$, and begins at $518^{\circ}$ to give off oxygen with a trace of chlorine; when heated until the evolution of gas ceases, chloride of silver remains. The evolution of oxygen is much more ready and rapid if the salt be mixed with oxide of copper or peroxide of manganese. If chlorate of silver be heated very rapidly, it decomposes suddenly with explosion and the extrication of light. When mixed with combustible bodies, it detonates by percussion much more strongly than the potash salt.

It is composed of

$$
\begin{array}{lr}
\text { Chloric acid .. } & 39 \cdot 37 \\
\text { Oxide of silver } & 60 \cdot 63 \\
\hline 100 \cdot
\end{array}
$$

If chlorine be passed through water containing oxide of silver in suspension, chlorate of silver is also formed; but if the current of chlorine be too long continued, this salt decomposes and oxygen gas is evolved, and there are formed chloride of silver and free chloric, not perchloric acid. By the action of hypochlorous acid on oxide of silver, or also upon finely divided metallic silver, no chloric acid is formed, but a mixture of peroxide of silver and chloride of silver.

Ammoniacal Chlorate of Silver.-Prismatic crystals of this salt are obtained by dissolving chlorate of silver in ammonia, and evaporating the solution; these crystals are very soluble in water and in alcohol; they melt at $212^{\circ}$ and lose their ammonia, and when the temperature does not exceed $534^{\circ}$ pure chlorate of silver remains ; when heated rapidly they decompose with explosion and the emission of light. The solution of this salt yields, on the addition of potash, a gray precipitate of Berthollet's fulminating silver.

This salt is composed of

$$
\begin{aligned}
& \text { Chlorate of silver .... } 84.81 \\
& \text { Ammonia .......... } \frac{15 \cdot 19}{100^{\circ}} \\
& \text { Journ. de Pharm. et de Ch., Mai } 1844 .
\end{aligned}
$$

\section{ON THE PROPERTIES AND COMPOSITION OF THE PROTOXIDE OF GOLD, BY M. L. FIGUIER.}

The modes of preparing the protoxide of gold proposed by the chemist above named were stated in the last Number of the Philosophical Magazine; we proceed now to state the

Properties of the Protoxide of Gold.-In the state of hydrate it is of so dark a violet colour as to appear black; when dried it has the violet-blue colour of the powder of Cassius. It does not decompose 
below $482^{\circ}$ Fahr., and it then yields oxygen ; it is insoluble in water, and is not either dissolved or decomposed by alcohol. Hydrochloric acid converts it into metallic gold which separates, and terchloride of gold which dissolves; this reaction requires a quarter of an hour to complete it when the acid is cold, but at a boiling heat it occurs instantaneously; in the former case protochloride of gold is at first formed, which itself afterwards decomposes by the usual reaction on the contact of water,

$$
3\left(A u^{2} \mathrm{Cl}\right)=A u^{2} \mathrm{Cl}^{2}+A \mathrm{u}^{4} .
$$

Hydriodic acid when brought into contact with protoxide of gold becomes of a deep yellow colour, and deposits protiodide of gold of a greenish colour. The supernatant liquor is a solution of protiodide of gold in hydriodic acid. If the whole be boiled, the iodine is disengaged in the form of violet vapours, and the gold is precipitated. There is not therefore produced, under these circumstances, a periodide of gold corresponding to the perchloride.

Hydrobromic acid acts like hydriodic acid; it gives when cold a brown deposit of bromide and becomes of a deep colour; if it be boiled the liquor becomes quite light-coloured; aqua regia dissolves the protoxide immediately, but neither sulphuric, nitric, nor acetic acid has any action upon it; potash and soda dissolve it only when in the nascent state; ammonia forms a violet fulminating compound; if rubbed with a hard body it explodes; but detonation is not so loud as that of the fulminating gold obtained with the teroxide of gold; hydrogen gas easily reduces it when hot, but without any sensible phænomenon.

Protoxide of gold ought to be arranged with indifferent chemical compounds, since it is capable of combining both with acids and bases; thus, while potash dissolves it in the nascent state (for example, during the treatment of the protochloride with this alkali) we shall find, on the other hand, that stannic acid readily combines with it.

'The extraordinary changeableness which Berzelius supposed to be a property of this protoxide, does not belong to it. It is in fact much less alterable than the teroxide of gold, which is a usual circumstance, for the first degree of oxidizement of a metal is in general more stable than the subsequent. Thus the protoxide of gold does not decompose below $482^{\circ}$ Fahr., whilst the teroxide undergoes it at $437^{\circ}$.

Direct light, which reduces the teroxide of gold after a certain time, has no action on the protoxide; there are, moreover, a great number of chemical agents which easily reduce the teroxide of gold, that have no action whatever on the protoxide; such for example are tartaric acid, acetic acid and alcohol.

When protoxide of gold has been dried, it is perfectly insoluble in water; but if at the moment of its preparation it be put into contact with distilled water, there is then produced what is called apparent solution; thus when an attempt is made to wash on a filter the protoxide obtained from the protochloride of gold by potash, it may be observed that a small portion of the product is carried off by the washing water, which passes through of a deep violet-blue colour. 
This liquor, when not strong, has the colour of weak tincture of litmus, but when concentrated it appears black; it remains clear for two or three days, but after this the oxide is entirely precipitated, and remains at the bottom of the vessel in the form of a blue cloud. The addition of a soluble salt to this liquor, when heated, occasions the instantaneous separation of the oxide, and a few drops of hydrochloric acid soon render it bright.

It does not always happen that distilled water produces the above described appearance, but the cause of the variation is not apparent; the mode of solution appears, however, to be similar to that of iodide of starch, prussian blue, \&c. \&c.--Ann. de Ch. et de Phys, Juillet 1844 .

PaRABolic ELEMENTS OF THE COMET Discovered BY $M$. VICTOR MAUVAIS, JULY 7,1844 , AS COMPUTED BY HIMSELF.

Time of perihelion passage, October $1844 \quad 14.7681$ Paris mean time. Logarithm of perihelion distance ..... $9 \cdot 8817875(q=0.7617)$ Longitude of perihelion......... $176^{\circ} 35^{\prime} 42^{\prime \prime}$

Longitude of the ascending node..... $35 \quad 3742$

Inclination ................. 494123

Motion ................. retrograde

Comptes Rendus, 15 Juillet, 1844.

METEOROLOGICAL OBSERVATIONS FOR JU I.Y 1844.

Chiswick.-July 1. Slight haze : cloudy: thunder, with rain from 6 till 8 P.sr. 2. Rain : cloudy. 3. Cloudy. 4. Slight rain: cloudy, 5, 6, Fine. 7. Hazy and mild : overcast. 8. Hazy: very fine. 9-11. Very fine, 12. Very fine: showery. 13. Rain : heavy rain at night. 14, 15. Clear and fine. 16. Overcast. 17. Fine : dusky clouds : hazy. 18. Very fine : cloudy. 19. Overcast : thunder quarter to 1 P.M. : thunder-showers in afternoon. 20, ?1. Clear and fine. 22. Cloudless and very hot. 23, 24. Sultry. 25. Very hot. 26. Cloudy: clear. 27. Hot and dry. 28. Very fine: cloudy. 29. Hot and very dry : exceedingly clear at night. 30. Overcast : rain. 3i. Cloudy and fine : clear.-Mean temperature of the month $1^{\circ}$ above the average.

Boston.-July 1. Fine : rain A.M. 2. Cloudy. 3. Fine. 4. Fine : rain P.M. 5. Rain. 6-8. Cloudy. 9-11. Fine. 12. Fine: rain $A, M$. 13. Fine : rain A.M. and P.M. 14. Stormy. 15. Fine: rain A.M., with thunder. J6. Fine : rain P.M. 17. Fine. 18. Fine: rain P.M., with thunder and lightning. 19. Fine: rain P. M. 20, 21. Fine. 22. Fine: thermometer $81^{\circ} 20^{\prime}$ clock P.M. 23. Fine :

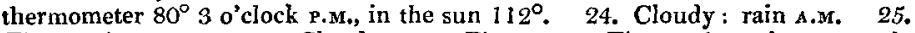
Fine : rain P.M. 26, 27. Cloudy. 28, Fine, 29. Fine: rain early A.m. : rain P.M. 30. Cloudy: rain P.M. 3I. Cloudy : rain, with thunder and lightning A.M.

Sandwick Manse, Orkney.-July 1. Cloudy. 2-6. Drizzle: showers. 7-9. Cloudy. 10. Cloudy : showers. 11. Showers: cloudy. 12. Damp: cloudy. 13. Bright: cloudy. 14. Cloudy. 15. Cloudy : clear, 16. Bright: clear. 17. Clear. 18. Clear : showers. 19. Cloudy : showers : drizzle. 20. Cloudy. 21. Cloudy : showers. 22. Cloudy : fine. 23. Clear: fine, 24. Bright: cloudy. 25. Clear: fine. 26. Clear: fog. 27. Clear: fine. 28. Bright: showers : fog. 29. Drizzle. 30. Cloudy. 31. Rain.

Applegarth Manse, Dumfries-shive.-July 1. Fine: a few drops of rain. 2-4. Fine : sultry. 5. Fine, but cloudy, 6. Slight shower. 7. Fine and fair. 8. Fine: a few drops of rain. 9. Fine, but cloudy. 10. Showers. 11. One shower. 12. A few drops of rain. 13. Heavy rain. 14. Showers : thunder. $15-17$. Showers. I8. Showers: thunder, 19. Slight shower: thunder. 20. Fair. 21. Wet all day. 22. Fine. 23. One heavy shower : thunder. 24-26. Rain : heavy P.M. 27. Beautiful day. 28. Showers. 29. Fair. 30, 31. Rain. 